\title{
Investigation on the Effect of Green Inhibitors for Corrosion Protection of Mild Steel in 1 M NaOH Solution
}

\author{
Premjith Jayakumar Ramakrishnan, Vishnu Deth Kaleekal Janardhanan, \\ Ramkumar Sreekumar, and Keerthy Parayil Mohan
} Mechanical Engineering Department, St. Joseph's College of Engineering and Technology, Mahatma Gandhi University,
Choondacherry, Pala, Kottayam 686579, India

Correspondence should be addressed to Premjith Jayakumar Ramakrishnan; mailtopremjith@gmail.com

Received 29 July 2014; Accepted 9 November 2014; Published 23 November 2014

Academic Editor: Flavio Deflorian

Copyright @ 2014 Premjith Jayakumar Ramakrishnan et al. This is an open access article distributed under the Creative Commons Attribution License, which permits unrestricted use, distribution, and reproduction in any medium, provided the original work is properly cited.

\begin{abstract}
Alkaline corrosion is one of the main issues faced by the industries. The main chemicals abundantly used in industries are $\mathrm{NaOH}$, $\mathrm{H}_{3} \mathrm{PO}_{4}, \mathrm{HCl}$, and $\mathrm{H}_{2} \mathrm{SO}_{4}$. Corrosion control of metals has technical, economical, environmental, and aesthetical importance. The use of inhibitors is one of the best options to protect metals and alloys against corrosion. The corrosion protection of mild steel in $1 \mathrm{M} \mathrm{NaOH}$ solution by mix of Henna/Zeolite powder was studied at different temperatures by weight loss technique. Adsorption, activation, and statistical studies were addressed in this work. Adsorption studies showed that inhibitor adsorbed on metal surface according to Langmuir isotherm. Surface studies were performed by using UV-spectra and SEM. The adsorption of inhibitor on the steel surface was found to obey Langmuir's adsorption isotherm. The inhibition efficiency increased with increasing concentration of the inhibitor in $\mathrm{NaOH}$ medium. Inhibition mechanism is deduced from the concentration and temperature dependence of the inhibition efficiency, Langmuir's adsorption isotherm, SEM, and UV spectroscopic results.
\end{abstract}

\section{Introduction}

Corrosion is the deterioration of metal by chemical attack or reaction with its environment. It is a constant and continuous issue, often difficult to avoid completely. Using corrosion inhibitors is a popular technique to prevent the corrosion rate of metals in chemical environments. Among the inhibitors, organic compounds act as good inhibitors due to their heteroatom structures such as sulfur, nitrogen, and oxygen [1]. By using these organic molecules on metal-solution interface, four types of adsorption may take place: (a) electrostatic attraction between the charged molecules and charged metal, (b) interaction of uncharged electron pairs in the molecule with metal, (c) interaction of p-electrons with metal, and (d) combination of (a) and (c). Most of these materials are toxic [2]. Recently, usage of toxic materials as inhibitors has been limited because of their environmental threat. The toxic effect does not only affect living organisms but also poison the environment. Due to the toxicity, research works are going on for investigating the inhibitive properties of plant extracts. Inhibitors in this class are those that are environmentally friendly and are obtained from natural products such as plant extracts [3]. Recently, several studies have been carried out on the inhibition of corrosion of metals by plant extract, essential oils, or purified compounds.

Among the so-called "green corrosion inhibitors" are organic compounds that act by adsorption on the metal surface, such as ascorbic acid [4], succinic acid [5], tryptamine [6], Garlic, Papaya Leaves, caffeine [7], and extracts of natural substances [8-12]. The objective of this work was the development of new hybrid inhibitor designed to produce an effective barrier against metal corrosion. In the present study, hybrid inhibitor was developed from Henna powder and Zeolite powder. The mild steel was chosen as a substrate due to its extensive use in many technological applications, consumer products, and specifically structures. The structural features 
TABLE 1: Inhibition efficiency and corrosion rate data of mild steel in $1 \mathrm{M} \mathrm{NaOH}$ in the absence and presence of inhibitor in different temperature and concentration.

\begin{tabular}{lcccc}
\hline Sl. number & Inhibitor concentration $(\mathrm{ppm})$ & Temperature $\left({ }^{\circ} \mathrm{C}\right)$ & Corrosion rate $\left(\mathrm{g} \mathrm{m}^{-2} \mathrm{~h}^{-1}\right)$ & Inhibition efficiency $(\%)$ \\
\hline 1 & \multirow{2}{*}{200} & 30 & 1.0940 & 85.00 \\
2 & & 50 & 1.9023 & 81.13 \\
3 & 70 & 3.9279 & 65.82 \\
\hline 4 & 400 & 30 & 0.4760 & 94.18 \\
5 & & 50 & 1.0652 & 89.43 \\
6 & \multirow{3}{*}{600} & 70 & 1.3520 & 82.23 \\
\hline 7 & & 30 & 0.2934 & 95.97 \\
8 & 50 & 0.9917 & 90.16 \\
9 & & 70 & 1.6620 & 85.54 \\
\hline
\end{tabular}

of the hybrid films were studied by SEM and UV-visible. The corrosion protection efficiency of the coatings on steel was studied by weight loss technique. The adsorption behavior is analyzed by Langmuir adsorption isotherm. The statistical analysis software MINITAB 16 was used for the design and analysis of experiments to perform the Taguchi and ANOVA analysis.

\section{Experimental Work}

MS specimen is used in the experiment. Specimens used for weight loss tests were of rectangular shape with size of $45 \mathrm{~mm} \times 30 \mathrm{~mm} \times 3 \mathrm{~mm}$. Prior to experiments, all specimens were polished by 100, 200, 400, and 600 grades of emery paper, washed with distilled water, degreased with acetone, dried in air, and kept in desiccators. Analytical grade $1 \mathrm{M}$ $\mathrm{NaOH}$ is prepared by the following method. To prepare $1 \mathrm{M}$ $\mathrm{NaOH}$ solution, $40 \mathrm{~g} \mathrm{NaOH}$ in a dry $1 \mathrm{~L}$ volumetric flask, add $900 \mathrm{~mL}$ distilled water and stir it until dissolved. Henna and Zeolite powder are mixed properly in equal proportion. The specimens were fully immersed for $2 \mathrm{~h}$ in $400 \mathrm{~mL} 1 \mathrm{M}$ $\mathrm{NaOH}$ solution at 30,50 , and $70^{\circ} \mathrm{C}$ and 200,400 , and $600 \mathrm{ppm}$ inhibitor concentration. After each experiment the specimens were washed with running tap water followed by distilled water, dried with clean tissue, immersed in acetone and benzene, and kept in desiccators over silica gel bed to dry and then weighed by high accuracy electronic balance. To test reliability and reproducibility of the measurements, duplicate experiments were performed in each case of the same conditions.

\section{Result and Discussion}

The corrosion of mild steel in $1 \mathrm{M} \mathrm{NaOH}$ solution containing various concentrations of inhibitor at different temperatures was studied by weight loss measurements. The corrosion rate of mild steel was determined using the relation:

$$
W=\frac{\Delta m}{S \times t},
$$

where $\Delta m$ is the mass loss $(\mathrm{g}), S$ is the area $\left(\mathrm{m}^{2}\right)$, and $t$ is the immersion period (day).
Weight loss measurements were carried out by weighing MS specimen before and after $2 \mathrm{~h}$ of immersion duration in $400 \mathrm{~mL}$ of solutions.

The inhibition efficiency (IE) was calculated as follows:

$$
\mathrm{IE} \%=\frac{W_{0}-W}{W_{0}},
$$

where $W_{0}$ and $W$ are the values of the weight loss of the without inhibitor and with inhibitor metal blocks, respectively.

Table 1 shows variation of inhibitor efficiency and corrosion rate with inhibitor concentration and temperature. It is clear that at certain experimental temperature, corrosion rate of steel decreases with an increase in concentration of inhibitor. In the absence and presence of a certain concentration of inhibitor, the corrosion rate of steel increases with rise in temperature, obeying the Arrhenius type reactions which will be discussed later. It was reported that the rate of iron corrosion in acid solutions approximately doubles for every $10^{\circ} \mathrm{C}$ rise in temperature [13]. Values of inhibitor efficiency increase with increasing inhibitor concentration.

3.1. Adsorption Studies and Inhibition Mechanism. The primary step in the action of inhibitors in alkaline solution is generally agreed to be adsorption on the metal surface. This involves the assumption that the corrosion reactions are prevented from occurring over the area (or active sites) of the metal surface covered by adsorbed inhibitor species, whereas these corrosion reactions occurred normally on the inhibitor free area [14]. Three representative Langmuir adsorption plots were obtained at different temperatures with various concentrations of inhibitor which are shown in Figure 1. The linear plots have the values of slopes equal to $0.94,1.00$, and 1.24 for the experimental temperatures of 30,50 , and $70^{\circ} \mathrm{C}$, respectively. These results could also indicate that some constituents of green inhibitor units occupied more than one adsorption site on the MS surface.

3.2. Statistical Analysis. The experimental corrosion rate results in uninhibited and inhibited $1 \mathrm{M} \mathrm{NaOH}$ as a function of temperature and inhibitor concentration are given in Table 1. The statistical technique known as analysis of variance (ANOVA) can be used. This technique based on variance 


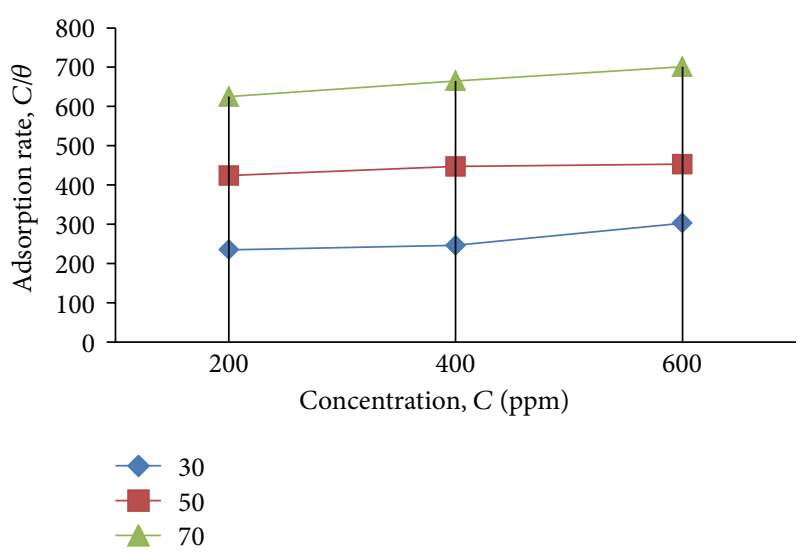

FIGURE 1: Langmuir adsorption isotherm for Henna/Zeolite powder on mild steel.

ratios to determine whether or not significant differences exist among the means of several groups of observation. Twoway ANOVA has been used in order to determine the effect of temperature and inhibitor concentration on inhibition efficiency.

Table 2 gives ANOVA result for inhibition efficiency. Fisher's $F$-test can also be used to determine which process parameters have significant effect on the performance characteristics. Usually, when $F$ value is large, it means that the change of the process parameter has a significant effect on the performance characteristics. It can be observed from Table 2 that inhibitor concentration has large $F$ value. Thus inhibitor concentration was found to be the major factor influencing inhibition efficiency at $55.68 \%$.

Figure 2 shows the effect of input parameters such as inhibitor concentration and temperature on inhibition efficiency. It can be observed that efficiency increases with increase in concentration and decreases with increase in temperature. Optimal input parameters for inhibition efficiency obtained $600 \mathrm{ppm}$ concentration and $30^{\circ} \mathrm{C}$ temperature.

3.3. Scanning Electron Microscope Study. Scanning electron microscope (SEM) images indicated the changes that accompany the corrosion and protection on the MS surface of the mild steel. Figure 3(a) shows the surface of polished MS specimen before immersion. Figure 3(b) revealed the formation of a protective layer by the constituents of green inhibitor. Figure 3(c) shows the damaged surface by the $\mathrm{NaOH}$ reaction after immersion. The micrograph of mild steel specimen without inhibitor shows a large number of pits and cracks due to the attack of aggressive corrosive medium.

3.4. UV-Vis Analysis. In order to confirm the possibility of the formation of Henna/Zeolite-Fe complex, UV-visible absorption spectra obtained from $1 \mathrm{M} \mathrm{NaOH}$ solution after mild steel immersions are shown in Figure 4(a) before immersion and Figure 4(b) after immersion. From the figures, the deviation is shown in absorbance values and their intensities. There is an increase in absorbance after mild steel
TABLE 2: Numerical values of ANOVA.

\begin{tabular}{lccccc}
\hline Source & DF & Adj. SS & Adj. MS & $F$ & \% Contribution \\
\hline Concentration & 2 & 352.10 & 176.05 & 10.52 & 55.68 \\
Temperature & 2 & 213.25 & 106.62 & 6.37 & 33.72 \\
Residual error & 4 & 66.93 & 16.73 & & 10.5 \\
\hline Total & 8 & 632.28 & & & \\
\hline
\end{tabular}

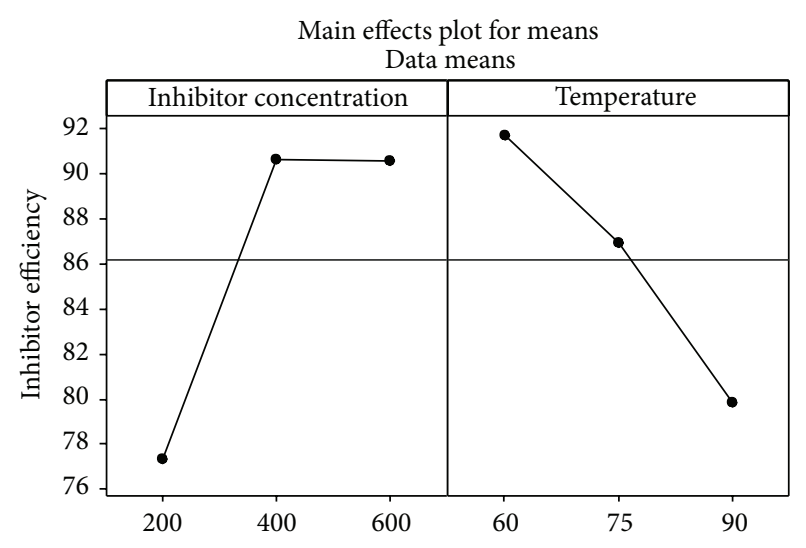

FIgURE 2: Main effect plot.

immersion in Henna/Zeolite powder added solution. This reveals the formation of a complex between the Fe ions and the phytoconstituents of the green inhibitors. Formation of this complex may be responsible for the observed deviation in the absorbance and its intensity value and this may be responsible for anticorrosion activity. It is also noted that there was significant difference in the shape of the spectra before and after the immersion of specimen showing the possibility of forming thin inhibitor layer over the mild steel surface (Physisorption).

\section{Conclusion}

Henna/Zeolite powder mix acts as a green corrosion inhibitor of mild steel with maximum inhibition efficiency of $95.97 \%$ at $30^{\circ} \mathrm{C}$ and maximum level of inhibitor concentration. Adsorption of inhibitor obeys Langmuir adsorption isotherm by forming a monolayer on metal. Statistical analysis shows corrosion rate influenced by temperature and inhibitor concentration. It is suggested from the confirmatory results obtained from SEM that the mechanism of corrosion inhibition is occurring through adsorption process. UV-spectra show that the compounds present in inhibitor form corrosion inhibitive layer by reacting with iron ions present on the mild steel surface.

\section{Disclosure}

Another thing is that Premjith Jayakumar Ramakrishnan, Ramkumar Sreekumar, and Keerthy Parayil Mohan are final 


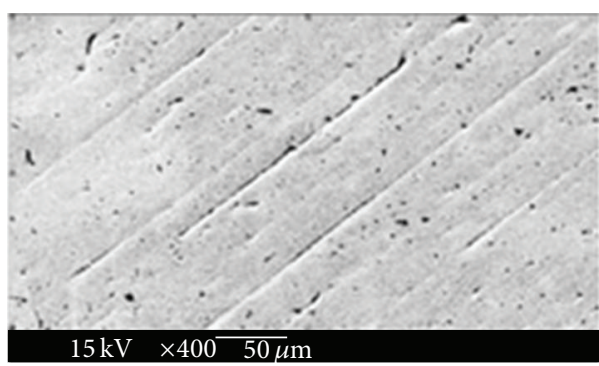

(a)

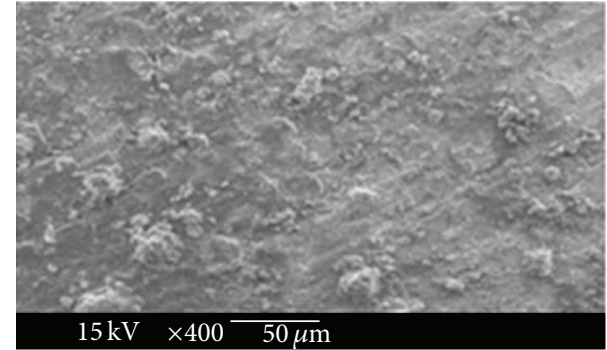

(b)

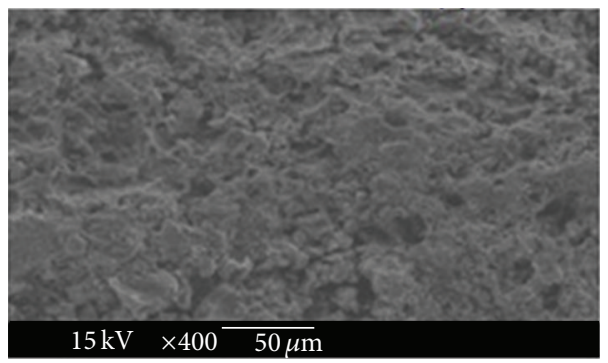

(c)

FIGURE 3: SEM images of MS specimen: (a) polished specimen before immersion, (b) specimen in $1 \mathrm{M}$ NaOH solution with inhibitor after immersion, and (c) specimen in $1 \mathrm{M} \mathrm{NaOH}$ solution without inhibitor after immersion.

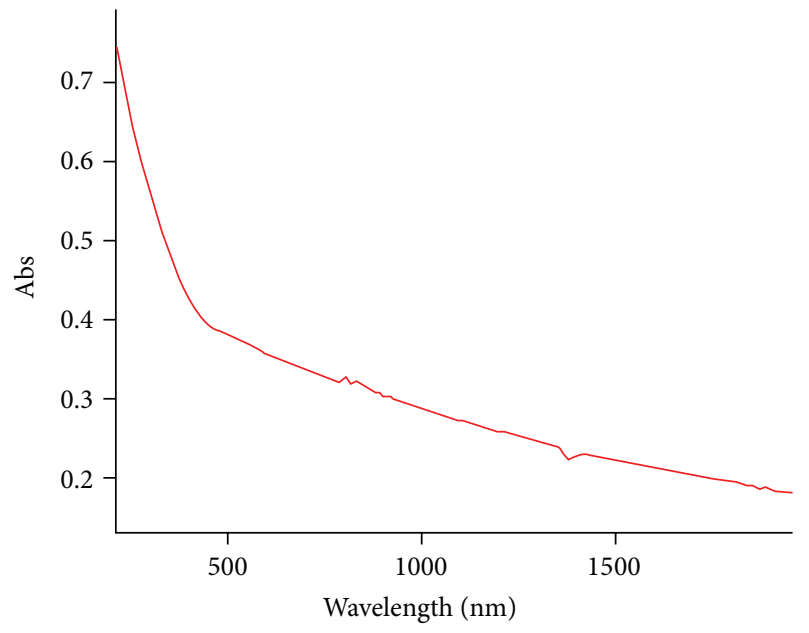

(a)

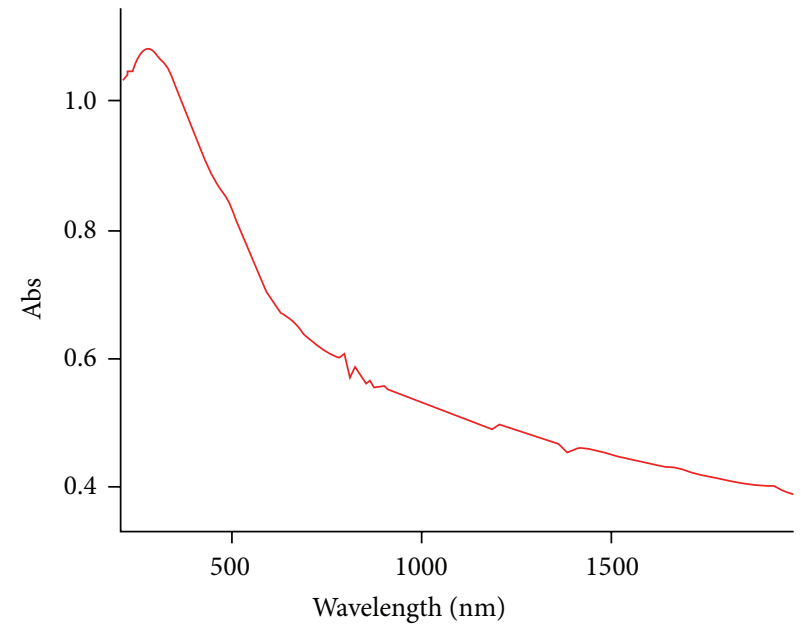

(b)

FIGURE 4: UV-spectra of MS specimen in inhibitor added $1 \mathrm{M} \mathrm{NaOH}$ solution (a) before immersion and (b) after immersion.

semester students of $\mathrm{M}$. Tech in advanced manufacturing engineering and production management at St. Joseph's College of Engineering and Technology, Kottayam, India. This paper is related to our final semester Project work. Vishnu Deth Kaleekal Janardhanan is the Assistant Professor in Mechanical Engineering Department of St. Joseph's College of Engineering and Technology, Kottayam, India.

\section{Conflict of Interests}

The authors declare that there is no conflict of interests regarding the publication of this paper.

\section{References}

[1] B. E. A. Rani and B. B. J. Basu, "Green inhibitors for corrosion protection of metals and alloys: an overview," International Journal of Corrosion, vol. 2012, Article ID 380217, 15 pages, 2012.

[2] A. Ostovari, S. M. Hoseinieh, M. Peikari, S. R. Shadizadeh, and S. J. Hashemi, "Corrosion inhibition of mild steel in 1 $\mathrm{M} \mathrm{HCl}$ solution by henna extract: a comparative study of the inhibition by henna and its constituents (Lawsone, Gallic acid, $\alpha$-D-Glucose and Tannic acid)," Corrosion Science, vol. 51, no. 9, pp. 1935-1949, 2009.

[3] A. Bernhoft, "Bioactive compounds in plants-benefits and risks for man and animals," in Proceedings of the Symposium 
Held at the Norwegian Academy of Science and Letters, Oslo, Norway, November 2008.

[4] E. S. Ferreira, C. Giacomelli, F. C. Giacomelli, and A. Spinelli, "Evaluation of the inhibitor effect of L-ascorbic acid on the corrosion of mild steel," Materials Chemistry and Physics, vol. 83, no. 1, pp. 129-134, 2004.

[5] M. A. Amin, S. S. Abd El-Rehim, E. E. F. El-Sherbini, and R. S. Bayoumi, "The inhibition of low carbon steel corrosion in hydrochloric acid solutions by succinic acid. Part I. Weight loss, polarization, EIS, PZC, EDX and SEM studies," Electrochimica Acta, vol. 52, no. 11, pp. 3588-3600, 2007.

[6] G. Moretti, F. Guidi, and G. Grion, “Tryptamine as a green iron corrosion inhibitor in $0.5 \mathrm{M}$ deaerated sulphuric acid," Corrosion Science, vol. 46, no. 2, pp. 387-403, 2004.

[7] T. Fallavena, M. Antonow, and R. S. Gonçalves, "Caffeine as non-toxic corrosion inhibitor for copper in aqueous solutions of potassium nitrate," Applied Surface Science, vol. 253, no. 2, pp. 566-571, 2006.

[8] A. Bouyanzer, B. Hammouti, and L. Majidi, "Pennyroyal oil from Mentha pulegium as corrosion inhibitor for steel in $1 \mathrm{M}$ HCl," Materials Letters, vol. 60, no. 23, pp. 2840-2843, 2006.

[9] P. B. Raja and M. G. Sethuraman, "Natural products as corrosion inhibitor for metals in corrosive media-a review," Materials Letters, vol. 62, no. 1, pp. 113-116, 2008.

[10] A. A. Rahim, E. Rocca, J. Steinmetz, and M. Jain Kassim, "Inhibitive action of mangrove tannins and phosphoric acid on pre-rusted steel via electrochemical methods," Corrosion Science, vol. 50, no. 6, pp. 1546-1550, 2008.

[11] L. R. Chauhan and G. Gunasekaran, "Corrosion inhibition of mild steel by plant extract in dilute $\mathrm{HCl}$ medium," Corrosion Science, vol. 49, no. 3, pp. 1143-1161, 2007.

[12] A. M. Abdel-Gaber, B. A. Abd-El-Nabey, I. M. Sidahmed, A. M. El-Zayady, and M. Saadawy, "Inhibitive action of some plant extracts on the corrosion of steel in acidic media," Corrosion Science, vol. 48, no. 9, pp. 2765-2779, 2006.

[13] H. H. Uhlig, Corrosion and Corrosion Control, John Wiley and Sons, 2nd edition, 1971.

[14] L. L. Shereir, Corrosion, vol. 2, Newnes-Butterworths, London, UK, 2nd edition, 1977. 

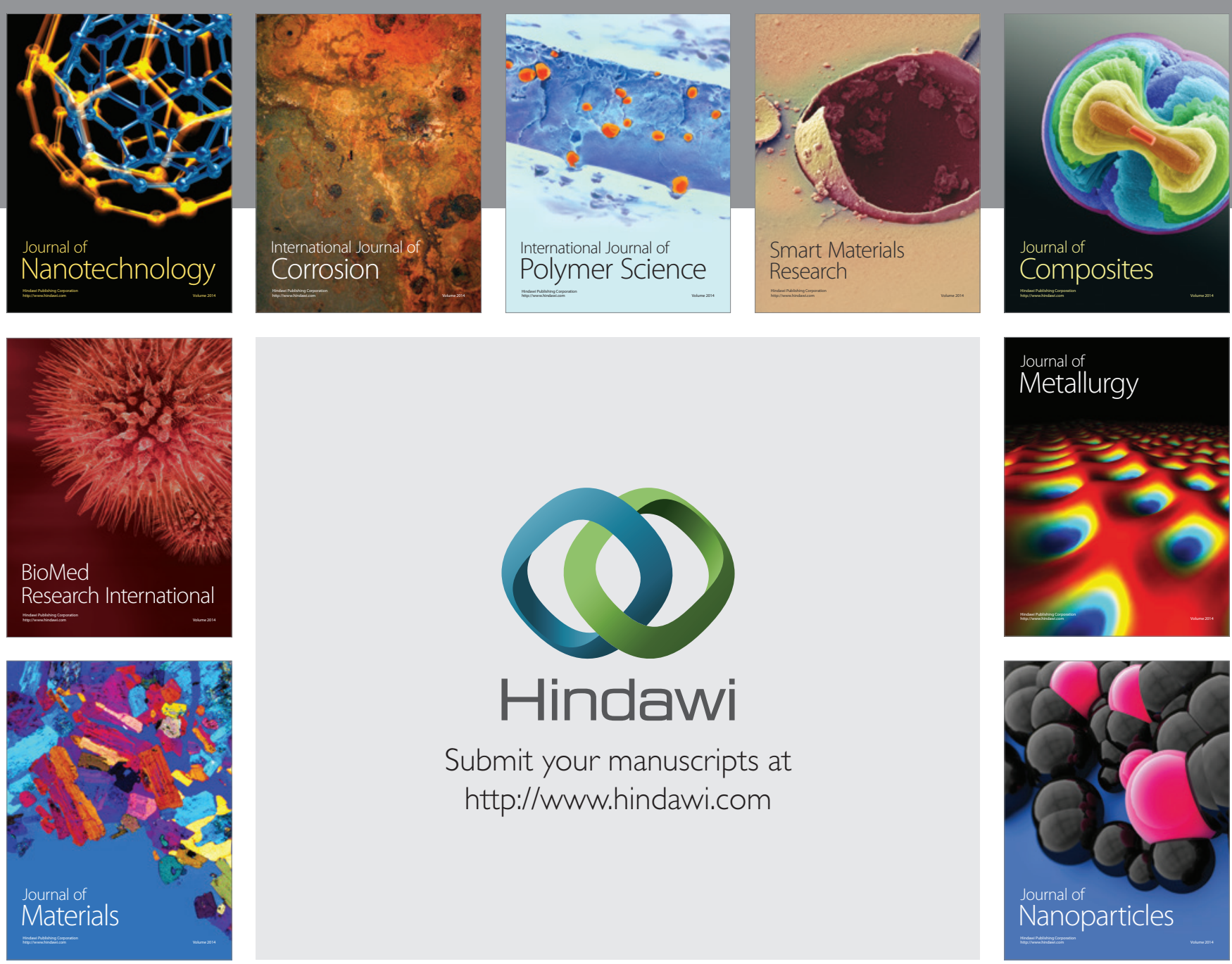

Submit your manuscripts at http://www.hindawi.com
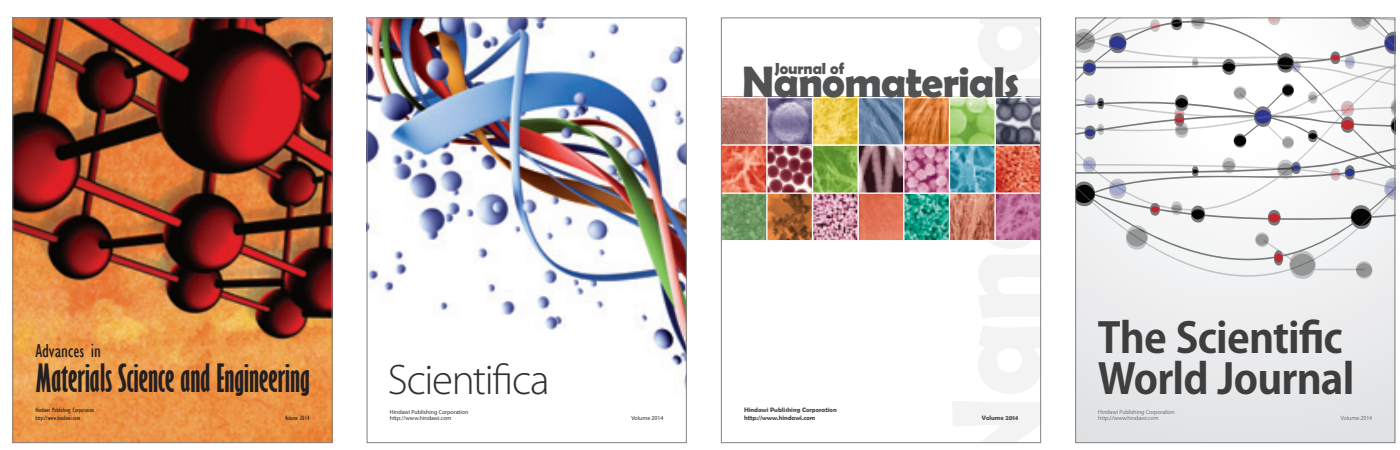

\section{The Scientific World Journal}
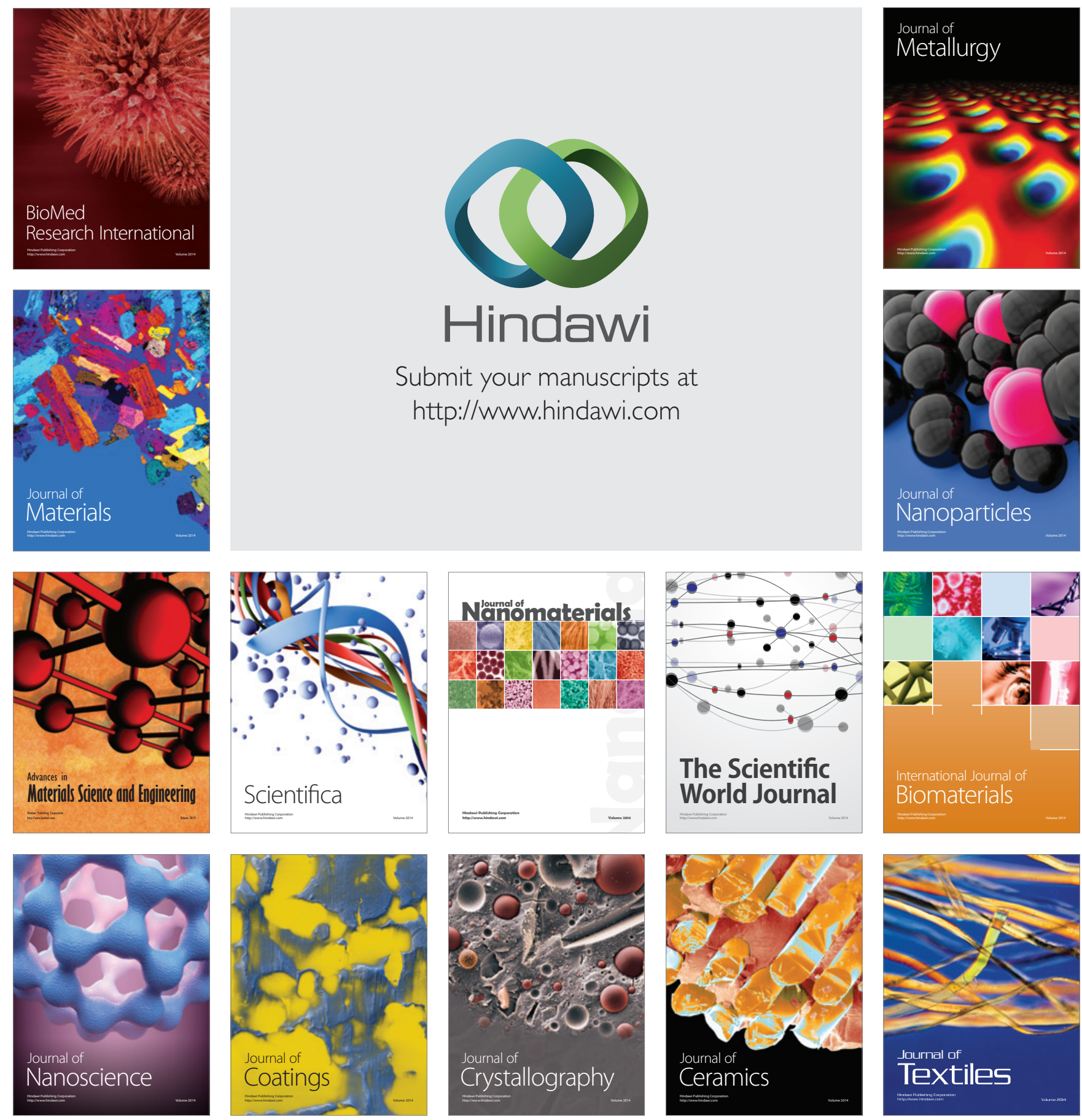